\title{
THE VERTICAL DIMENSION OF INTER-PROFESSIONAL POWER AND CONFLICT
}

\author{
Paul D. Nugent, Western Connecticut State University,nugentp@wcsu.edu
}

\begin{abstract}
This paper draws upon empirical studies and organization theory to analyze a trend that has been occurring in professional bureaucracies from the mid-1990s to today. A newer generation of quality control systems leverages the philosophy and legitimacy of earlier manufacturing-based quality control programs such as Quality Circles (QC), Statistical Process Control (SPC), and Total Quality Management (TQM) and applies them to work that is being performed by professional workers in bureaucracies. These include Six Sigma, Capability Maturity Model Integration (CMMI), Lean, and Information Technology Infrastructure Library (ITIL), as well as other similar programs found in higher education, hospitals, law firms, and government agencies. This introduces a new professional group, the "process owners," that now competes with the existing professionals, the "local professionals," for authority over work jurisdictions within an organizational hierarchy and therefore represents a vertical dimension of interprofessional competition that so far has received little scholarly attention and has implications for organization theory and management.
\end{abstract}

Keywords: Occupations, Professions and Work; Institutional Theory; Knowledge Flows and Knowledge Management

\section{INTRODUCTION}

Organizations are indeed powerful and capable of improving the lives of human beings as the conference theme invites us to explore. Whether it is from an ethical commitment or from day-to-day "business as usual," there is little doubt that many of the workers engaged in such life-improving labor are professionals - professors, politicians, lawyers, engineers, managers, economists, scientists, teachers, physicians, etc. Furthermore, the majority of these professionals do not perform their work in a standalone or isolated fashion any more, but rather are employees in what is often referred to as a "professional bureaucracy" - e.g., university, corporation, government agency, school, hospital and so forth.

This raises the question of how do these professional bureaucracies enable, constrain, motivate, or potentially alienate the professionals over whom they have some degree of power and control? There is little doubt that automation and bureaucratization of wage labor or "blue collar" work led to estrangement and alienation throughout the twentieth century (Roy, 1954; Braverman, 1974; Burawoy, 1979). However, despite Weber's characterization of bureaucracy as an impersonal "iron cage" that was bound to flourish because of its objective efficiency, there are those who have found that it also offers technical, social, and political resources for self-actualization and development, especially for professionals (e.g., Adler \& Borys, 1996; Adler, 2011).

Throughout the twentieth century this was the norm and researchers of professional workers in these bureaucracies found ample evidence of these positive outcomes and, in contrast to wage laborers, very little evidence of alienation (Bailyn, 1985; Becker, 1961; Dalton, 1959; Gouldner, 1954; Jackall, 1988; Kanter, 1977; Kunda, 1992; Roethlisberger and Dixon, 1939; Rohlen, 1974; Rosen, 1984; Smith, 1971; Whyte, 1956). By and large management handled the "business side" of the equation and allowed the professional a great deal of autonomy in carrying out their professional duties.

However, in the 1990s this began to change. The success of what I will call "first-generation" quality control programs (e.g., Quality Circles (QC), Statistical Process Control (SPC), and Total Quality Management (TQM)) in improving productivity in manufacturing processes began to migrate "up stream" in the organization and be applied to nonmanufacturing processes carried out by professional workers. Chances are you, the reader of this paper, are a professional working in a professional bureaucracy and have witnessed this shift in some way. For example, 


\section{Issues in Information Systems \\ Volume 19, Issue 1, pp. 29-38, 2018}

universities establish or maintain accreditation by demonstrating to accrediting agencies, through formal goals and metrics, that they are continuously improving. Similar programs are being imposed at the enterprise level in hospitals, law firms, and government agencies. And if you are a professional in a corporation, you will likely have witnessed the integration of Six Sigma, Capability Maturity Model Integration (CMMI), or Lean programs. I will refer to these as "second-generation" quality control (QC) programs.

Virtually all professional bureaucracies in the western world have experienced a shift in which both the knowledge required to perform professional tasks and the responsibility for evaluating the quality of the product or service are being transferred from the professional herself to management or to what is often referred to as a subset of management/administration called the "process owners." It is not surprising then, that researchers have found evidence that while the professional was able to avoid alienation prior to this shift, they now suffer from some of the same forms of alienation that their blue-collar counterparts have experienced from industrialization and automation (Nugent, 2017; Nugent \& Collar; 2017).

While this story is important in its own right, this paper strives to move beyond the phenomenological effects of this shift and instead focus on what it means to the literature on the institutional dynamics of professional groups. In particular, the shift outlined above represents a contested terrain between the professionals themselves who, either individually or collectively, have through time developed their "traditional" or "own ways" of doing things and the new "process owners" who are simultaneously trying to migrate that tacit knowledge to formal organizational processes and evaluate the quality of organizational outcomes.

Weber's notions of traditional versus rational-legal forms of authority are useful in framing this contested terrain and in contemplating the significance of informal/clan controls in value creation. In addition, Andrew Abbott's (1988) analysis of professions serves as an analytical context within which to think about jurisdictional competition among professional groups and how the emergence of second-generation QC programs introduces an interesting new axis of competition. While most scholarly attention to professional competition is across groups in various professional practices or bureaucracies, we now see a new axis of competition between professionals that is within the same institution. This provides a context within which to conceptualize a vertical in addition to a horizontal dimension of inter-professional competition for jurisdictional control, power, and legitimacy.

\section{BACKGROUND AND LITERATURE REVIEW}

According to Andrew Abbott (1988), professional work differs from other kinds of work because it draws on an extensive abstract body of knowledge to diagnose and treat complex problems. Therefore, not only are professionals more likely to be in positions to treat problem that can improve life for people in line with the conference theme, it they can only do this well if they are familiar with abstract bodies of knowledge that bear on classes of problems. Abbott's analysis is particularly interesting because he looks at profession as a complex institutional system in which professional groups vie with one another for legitimacy regarding treatments of particular problem areas (jurisdictions). For example, professionals who practice alternative medicine or acupuncture are competing with the mainstream medical profession to treat specific kinds of health problems. Abbott shows how these competitions for professional jurisdictions are dynamic and professions need to be strategic in order to establish and maintain legitimacy in jurisdictional areas (Abbott, 1988).

Underexplored in Abbott's analysis is the possibility for two groups of professionals to be in competition with one another for a jurisdictional space within the same organizational hierarchy. His analysis does discuss internal stratification and differentiation for a particular professional group, but this is restricted to "degradation" where some in the professional group are relegated to more routine tasks while those of higher accomplishment and status enjoy the professionally "purer" non-routine tasks (Abbott, 1988). Interestingly this buffers those at the higher levels from the public-facing tasks so that they can focus on problems internal to their professional abstract body of knowledge. But while this may introduce inter-group conflicts and divisions of labor along lines of specialization, there is still no attention paid to the possibility that two professional groups, with different abstract bodies of knowledge, may vie for jurisdictional space within the same hierarchy. In what follows we will see how second-generation QC programs 


\section{Issues in Information Systems \\ Volume 19, Issue 1, pp. 29-38, 2018}

evolved from first-generation QC and have introduced a new professional group or administrative layer that competes with the existing (local) professional groups for control over quality as well as process knowledge.

\section{First-Generation QC Programs}

Second-generation QC grew out of the first-generation of quality control which initially included "quality circles," "statistical process control," and Total Quality (TQ) later to all be included under the umbrella term Total Quality Management (TQM) (Giroux \& Landry, 1998, Feigenbaum; 1989). Adopting Barley and Kunda's (1992) categorization of institutions as imposing normative and rational types of control, Giroux \& Landry (1998) show how both of these types of control were central to TQM adoption and implementation. Specifically, the rational facet of TQM stressed viewing production as a "system" with sources of variation that need to be controlled and that poor quality was the result of poor management and not to be blamed on the worker (Giroux \& Landry, 1998). In contrast, the normative school holds the worker more responsible and attempts to change the entire culture of the organization to embrace quality goals,

...the normative school's basic hypothesis is that poor quality can largely be attributed to worker negligence and to company-wide carelessness. In this context, the objective is to develop and disseminate a flawless argument to illustrate the role played by the individual in attaining quality (with management setting the example) and to stress economic rationality and the performance obligation facing the company. (Giroux \& Landry, 1998). [p. 188]

Therefore, through both rational and normative pressures, first-generation QC programs were able to flourish in organizations and gain field-wide legitimacy, especially in industrial and technical fields (Powell \& DiMaggio, 1991).

These QC programs represented a critical, fundamental, and irreversible shift in organizational control and responsibility. According to (Giroux \& Landry, 1998),

The introduction of the concept of "Total Quality Control" (TQC) represented a turning point in quality management because it attributed the responsibility for finished product quality to a large number of key individuals. Ultimately, responsibility was spread over the entire company "Company-Wide Quality Control" - and involved not only functions directly related to product creation but also all company services involved in supplying production support and resources. [pp. $186,187]$

Therefore, first-generation QC programs succeeded in creating an organizational logic in which management claimed primary responsibility for product/service quality while the workers were trained to value quality as and enterprisewide goal. Most significantly, however, these programs were not isolated to particular departments or manufacturing processes, but spanned the entire organization's work roles and processes. Only with this stage being set could the second-generation QC programs gain legitimacy and traction within professional bureaucracies.

\section{The Widespread Adoption of Second-Generation QC Programs}

Although the objective performance of first-generation QC programs has been debated by scholars (e.g., Landen \& Landen, 1990; Bemowski, 1993; Hill, 1995; Schafer \& Thomson, 1992; Giroux \& Landry, 1998), an organizationwide program for defining quality, measuring processes, and controlling variation became a philosophy that, in line with Weber, reflected an undeniable rationality.

This set the stage for newer kinds of QC programs that could be extended to work being performed by professionals. Process control philosophies originally conceived for exclusively mechanical processes were now being applied to human and social organizational processes. As such they represent a further rationalization or bureaucratization of work activities and processes (Gerth \& Mills, 1946; Waters, 1989; Adler, 2011). Furthermore, more specific to our purposes here, second-generation QC programs tend to focus on two primary facets or objectives which are, as with first-generation QC the control of process variation, but now we see an explicit migration of task knowledge from the worker to formal best practices and its standardization across the enterprise - sometimes referred to in the management literature as "knowledge management" (Alavi \& Leidner, 2001). Let us now turn to these two basic aspects of secondgeneration QC programs. 
Statistical Process Control Focus. Second-generation QC programs draw from the rational school of first-generation QC by applying statistical and "systems thinking" philosophies whereby for any meaningful organizational process there should be some predicted/expected variability that can be measured and monitored for excessive or undesirable levels of variation in control-chart fashion. Some sources of process variation are considered to be normal and are called "common-cause" variation because they acknowledge the multiple random sources of variation that are inherent to the production process. In contrast, "special-cause" sources of variation are unwanted and represent some abnormal shift in the process that needs to be understood, through "root-cause analysis," and eliminated.

Six Sigma and Capability Maturity Model Integration (CMMI) are examples of the more popular second-generation QC programs that depend heavily upon these kinds of statistical process measurement, control, and framing of organizations as processes within larger systems. For example, in engineering settings "peer reviews" or "gate reviews" are critical organizational processes/activities in which subject matter experts and stakeholders formally review a product and identify issues. CMMI assumes that these processes should have some regularity with respect to how many "defects" should be expected in a particular kind of review. It then statistically monitors the number of defects across reviews and looks for any unusual spike that would indicate some unwanted "special cause" to be investigated and eliminated.

Although this control philosophy is also well-represented in other professional settings such as universities or other institutions that need to establish and maintain accreditation from some external authority, they have been widely adopted by more technical professional bureaucracies.

Knowledge Management Focus. Lean and Information Technology Infrastructure Library (ITIL) represent secondgeneration QC programs that also embrace the process control philosophy however their main focus is on capturing the critical knowledge inherent in a process or best practice. It is rational to minimize arbitrary variation in processes across the organization, identify what is considered to be the best practice, codify it, and standardize it. In concert, knowledge management also strives to manage the cultivation and transference of expert knowledge within the organization. For example, if a group of engineers that has been working on a particular system for a particular customer for decades, they will possess what some refer to as "profound knowledge" embodying both social capital and intellectual capital, and as that group nears retirement age or will depart for other reasons, it is important for the organization to ensure that this valuable knowledge is transferred by various means (e.g., "knowledge management plans," mentoring, etc.) to others in the organization (Alavi \& Leidner, 2001).

These trends have distinct implications for professionals and how they perform their work. Prior to second-generation QC programs, the individual professional or professional group enjoyed a great deal of autonomy over how to draw from an abstract body of knowledge, as well as from their locally cultivated routines, to diagnose and treat problems. In the analysis we will turn our attention to the evolution of a new professional group, the "process owners" that can be viewed as taking away from the original professionals, what I will refer to as "local professionals," power, and control over process definition and quality.

\begin{abstract}
ANALYSIS
Labor studies has traditionally been focused on the conflict between "management" and "wage laborers" and worker alienation. But while the alienation story is an important one, the focus of this study is to think about how secondgeneration QC programs introduce an abstract body of knowledge that is employed by a new type of professional that is emerging across professional bureaucracies that needs to be accounted for and understood. These "process owners" typically involve those in upper administrative and managerial roles. This term also coincides with language used in technical settings by engineers and managers in referring to these roles and role occupants (Nugent, 2017). In contrast to the process owners, there are the "local professionals" that represent those who executed, controlled, and evaluated organizational processes in localized spheres (e.g., departments) prior to the proliferation of both first and secondgeneration QC. These two groups coexist within the same hierarchy and represent a vertical form of inter-professional competition.
\end{abstract}




\section{Issues in Information Systems \\ Volume 19, Issue 1, pp. 29-38, 2018}

To more fully understand the nature of this competition, we will now turn our attention to Weber's analysis of authority and how each of these professional groups is primarily influenced by different types of authority - in particular legalrational versus traditional forms of authority.

\section{Traditional versus Legal-Rational Forms of Authority}

Max Weber's distinction between various forms of authority is useful in thinking about how the two professional groups, process owners and local professionals differ from each other in meaningful ways. In particular, the widespread adoption of second-generation QC and the emergence of process owners represents a legal-rational form of authority that comes into conflict with the local professionals who are governed to a greater extent by traditional authority (Waters, 1989). This has interesting implications for the dynamics of bureaucratization in general and for the specific vertical competition for jurisdictions between the process owners and the local professionals.

To Weber there are three general types of authority: traditional, charismatic, and legal-rational (Gerth \& Mills, 1946). Traditional authority is usually associated with feudalism and patrimonialism and is passed from generation to generation. Traditional authority is, therefore, somewhat arbitrary, developed by the group, and in earlier times served to control various forms of servitude. Charismatic authority rests in an individual's ability to motivate and inspire others through their personality, communications, and missionary zeal. In contrast, legal-rational authority undergirds the more modern forms of organization such as bureaucracies and professional institutions and appeals to existing established laws or to "natural laws" (rationality) (Gerth \& Mills, 1946). Weber believed that modernity is characterized by a gradual erosion of traditional and charismatic forms of authority that is inevitable due to bureaucracy's objective superiority in terms of efficiency and control.

This demarcation between types of authority is especially evident in the two types of professionals (process owners and local professionals) identified above. Process owners claim legal-rational authority rooted in the TQM philosophy whereas local professionals are governed primarily by traditional authority cultivated through decades of professional experience. As authority and power are closely aligned, many scholars have associated legal-rational authority with "formal control" and traditional authority with informal or "clan control" and have explored which type of control is most effective in modern organizations (Long et. al., 2002; Kirsch et. al, 2002; Parsons, 2003; McGarry \& Sweeney, 2007; Wiener et. al. 2015; Henry et. al., 2015). The results of these studies make it clear that informal/clan controls are important complements to formal controls and their effectiveness is usually moderated by cultural and contextual factors. For example, Choudhury \& Sabherwal (2003) found that informal controls contributed to effectiveness in outsourced software development projects in the presence of shared goals and frequent interactions between clients and vendors. A strong theme throughout these studies is that there is no single form of control that is best and that informal and formal controls complement one another and their effectiveness is often the result of contextual (social) factors (Kirsch et. al., 2002; Burton \& Van den Broek, 2009; McGarry \& Sweeney, 2007; Wiener et. al., 2015).

Yet, these studies could do more to elaborate these contextual factors and to understand the bases of informal/clan control and how shifts away from it toward formal control could be problematic in professional settings. Clan control, governed by traditional authority, reflects a bottoms-up cultivation of process knowledge and social relations embedded in the work activities. Waters (1989) refers to this phenomenon as "collegiate structure" and states: "Collegial structures are those in which there is dominant orientation to a consensus achieved between the members of a body of experts who are theoretically equal in their levels of expertise but who are specialized by area of expertise." [p. 956]. Furthermore, collegial structures, in concert with Abbott's framing of professionals, are characterized by theoretical knowledge, careers, formal egalitarianism, formal autonomy, scrutiny of product via peer review, and collective decision-making (Waters, 1989). Waters also acknowledges that different kinds of organizations will possess different proportions of administrative versus collegial power (Waters, 1989).

It is in this vein that we can now consider why "collegiate structure" or clan control based upon traditional authority is effective in professional bureaucracies and in so doing better understand the jurisdictional space that the process owners are encroaching upon and its overall implications for organizational performance. To better understand the institutional context of this conflict we will draw on the new institutionalism in organizational studies as well as knowledge management and the notions of "profound knowledge." 


\section{The New Institutionalism and the Positive Functions of Informal Control}

According to the "new institutionalism" in organization theory, organizational scholars have shifted from a focus on institutions as rational and goal-oriented structures to more decentralized decision-making arenas in which informal communication and control play a significant role in organizational outcomes (Powell \& DiMaggio, 1991). Institutional scholars claim that organizational structure results from social trust or implicit expectations that each interested party is doing its part to the best of its abilities and resists formal evaluation by external authorities and criteria:

Institutionalized organizations protect their formal structures from evaluation on the basis of technical performance: inspection, evaluation, and control of activities are minimized, and coordination, interdependence, and mutual adjustments among structural units are handled informally. [Powell \& DiMaggio, 1991, p. 57]

This mean that, at least prior to second-generation QC programs and "process owners," the local professionals were granted a great deal of trust and autonomy in their production activities. Continuing along this line, in institutions there exists a "logic of confidence and good faith," (Powell \& DiMaggio, 1991, p. 58) in which:

Considerations of face characterize ceremonial management. Confidence in structural elements is maintained through three practices - avoidance, discretion, and overlooking. Avoidance and discretion are encouraged by decoupling autonomous subunits; overlooking anomalies is also quite common. Both internal participants and external constituents cooperate in these practices.

Delegation, professionalization, goal ambiguity, elimination of output data, and maintenance of face are all mechanisms for absorbing uncertainty while preserving the formal structure of the organization. [p. 58]

As a result, formal inspection and evaluation of the group's output is minimized. According to Powell \& DiMaggio (1991):

Evaluation and inspection are public assertions of societal control which violate the assumption that everyone is acting with competence and in good faith. Violating this assumption lowers morale and confidence. Thus, evaluation and inspection undermine the ceremonial aspects of organizations. [p. 59]

In this context, then, prior to second-generation QC and the emergence of process owners, there existed a division of labor and an implicit trust that professionals were doing what they do best and the organization ceremonially granted them almost full autonomy. Second-generation QC programs directly violate these institutional conventions by claiming that the process owners, and the body of knowledge from which they draw upon, are now applicable to these jurisdictions (quality evaluation, process definitions, etc.).

\section{The Limits of Knowledge Management in Professional Bureaucracies}

In this section, we will turn our attention to the abstract bodies of knowledge that each of the professional groups that are in vertical competition draw from and what this means to organizational outcomes.

Let us begin with an examination of professional work itself and the types of knowledge required to perform it well. Engineers draw on design principles and current technology to design new systems, doctors keep abreast of the latest methods to best diagnose and treat an illness, professors keep up to date in their fields to ensure that their curricula are relevant, lawyers attend to shifting laws and ethical contexts, etc. Therefore, in addition to acquiring an abstract body of knowledge in obtaining a professional degree or certification, professional and groups of professionals are responsive to the fact that these bodies of knowledge are in flux. In addition to staying current, groups of professionals in organizations cultivate their own local processes for handling all facets of professional production including unique relationships with technicians, support staff, administrators, and clients. A great deal of the division of labor and role expectations are negotiated over time by knowledgeable agents (Barley, 1996; Barley \& Orr, 1997). In addition, each professional is embedded in a web of relations from which they have access to time-critical information and other resources for performing their professional duties (Bourdieu, 1986; Powell, 1990; Nahapiet \& Ghoshal, 1998). 


\section{Issues in Information Systems \\ Volume 19, Issue 1, pp. 29-38, 2018}

For our purposes here, this means that the work itself requires highly idiosyncratic knowledge about stakeholders, locally cultivated (traditional) processes, technologies, network contacts, and institutional memory that some scholars refer to as "tacit" or "profound knowledge," and is supports core organizational function (Fukuyama, 1995). This is the body of knowledge that the local professionals use to perform their work successfully.

The process owners, in contrast, draw from a more general knowledge base to claim authority over some of the same jurisdictional spaces that were previously claimed exclusively by the local professionals and their traditional authority. As touched upon earlier, the jurisdictional "contested terrain" is primarily in the areas of quality evaluation/control and knowledge management. Prior to second-generation QC programs local professionals draw on their profound knowledge to define processes/activities and their peer-to-peer "collegial structure" to obtain a consensus over product quality. Process owners, in contrast, are removed from the idiosyncrasies of the production process and instead gather abstracted data (metrics) on organizational process outcomes that they believe should exhibit some level of statistical regularity (e.g., if it is Six Sigma or CMMI), or to the extent that the local professional's idiosyncratic knowledge may be considered a best practice, they transform that previously tacit and localized knowledge into explicit codified processes/procedures and standardize them across the organization where they could be common (e.g., ITIL, Lean).

In either case, the process owners draw on their professional body of knowledge to make simplifying assumptions about the products and processes that are, in reality, highly complex and they shift the responsibility and accountability for product quality away from the local professional to management and together these trends can lead to production failures (Nugent \& Collar, 2017). For example, according to an engineer in a study of CMMI in a defense contracting company,

My own personal opinion of CMM and CMMI from a business point of view in a competitive environment, it is critical to have that as a shingle hanging on the door. It gives the appearance of a certain amount of predictability, it gives the appearance of manageability and control. To some extent you have manageability and control artifacts, but your product is not a set of artifacts. Your product is a system that works in the end. You know, if your system does not work but you have beautiful artifacts, it did no good whatsoever. (Nugent \& Collar, 2017, p. 20)

This means that the local professionals often ignore, or simply endure, the "overhead" of producing artifacts (metrics and reports) for the process owners and need to fall back on their professional ethics and traditions to ensure that the final outcome meets their quality requirements (Durkheim, 1957; Abbott, 1988).

In summary, it seems that empirically and theoretically the vertical competition between process owners and local professionals for jurisdiction has little positive benefit to the core functions of the professional bureaucracy. Ultimately it is the local professionals who possess the profound knowledge required for structuring the work and ensuring quality while the process owners monitor that quality at a level of abstraction to maintain he appearance of control to external stakeholders.

\section{Institutional Pressures to Adopt Second-Generation QC Programs}

If the adoption of second-generation QC programs has no obvious benefit to production in a professional bureaucracy, then how did they come to proliferate as early as the 1990s up to today?

According to the new institutionalism, organizations are pressured into copying best practices that leading organizations in their field have adopted. This process is called mimetic isomorphism because it simultaneously copies a practice and makes each organization structurally more similar to the others (Powell \& DiMaggio, 1991). These pressures have much more to do with maintaining legitimacy to external stakeholders than they do objective internal efficiency and effectiveness. The engineer's quote in the previous section acknowledges this phenomenon quite well - especially with his emphasis on "appearance." Much of what second generation QC programs do is to establish and maintain institutional level legitimacy in the eyes of customers and other external stakeholders. However, as the quote also emphasizes, its internal effectiveness in creating a "product" is illusory. What makes a good product, instead, is a function of clan/informal controls of system experts who understand the complex details of the system being built and its technical, social, and political contexts. This critique of second-generation QC programs, especially CMMI, is echoed in other sources as well (Fine, 2001; Shang \& Lin; 2009; Nugent \& Collar, 2017). 


\section{Issues in Information Systems}

Volume 19, Issue 1, pp. 29-38, 2018

\section{SUMMARY AND RECOMMENDATIONS}

In this paper we have considered a vertical form of inter-professional competition that so far has received little scholarly attention. This competition is the result of the emergence of second-generation QC programs that cultivate a new professional group, the process owners, that claim authority over production knowledge and quality previously enjoyed exclusively by the local professionals.

Based upon some empirical studies as well as organization theory, there are good reasons to believe that the adoption of second-generation QC programs is in response to institutional pressures at the field level and has no obvious positive effect on internal organizational performance. Rather, this shift burdens the local professional with additional overhead to product artifacts for the process owners and in shifting responsibility for organizational outcomes away from the local professional to the process owners runs the risk of poorer quality if the local professionals do not continue to embrace their professional ethics, production traditions, and collegiate structure.

As management will continue to experience (institutional pressures to adopt and maintain second-generation QC programs, it is recommended that they factor in these organizational/professional dynamics into their planning to prevent the vertical competition from taking away the profound knowledge of the local professionals that lies at the core of the success of any professional bureaucracy.

\section{REFERENCES}

Abbott, A. (1988). The System of Professions: An Essay on the Division of Expert Labor. Chicago: Univ. of Chicago Press.

Adler, P. \& Borys, B. (1996). Two Types of Bureaucracy: Enabling and Coercive. Administrative Science Quarterly, 41, 61-89.

Adler, P. (2011). The sociological ambivalence of bureaucracy: from Weber via Gouldner to Marx. Organization Science online. March 23, 244-266.

Alavi, M \& Leidner, D. E. (2001). Review: Knowledge Management and Knowledge Management Systems: Conceptual Foundations and Research Issues. MIS Quarterly, Vol. 25 No. 1, pp. 107-136. March.

Bailyn, L. (1985). Autonomy in the Industrial R\&D Lab. Human Resource Management 24: 129-146.

Barley, S. R. \& Kunda, G. (1992). Design and Devotion: Surges or Rational and Normative Ideologies of Control in Managerial Discourse. Administrative Science Quarterly (September): 363-399.

Barley, S. R. (1996). Technicians in the Workplace: Ethnographic Evidence for Bringing Work into Organization Studies. Administrative Science Quarterly, 41: 404-441.

Barley, S. R. \& Orr, J. E. (eds.) (1997). Between Craft and Science: Technical Work in U.S. Settings. ILR Press: Ithaca.

Becker, H. (1961). Boys in White. Chicago: University of Chicago Press.

Bemowski, K. (1993). Quality, American Style. Quality Progress (February): 65-69.

Blau, P. M. \& Meyer, M. W. (1987). Bureaucracy in Modern Society. $3^{\text {rd }}$ ed. Random House.

Bourdieu, P. (1986). The Forms of Capital. In J. G. Richardson (Ed.), Handbook of Theory and Research for the Sociology of Education: 241-258. New York: Greenwood. 


\section{Issues in Information Systems}

Volume 19, Issue 1, pp. 29-38, 2018

Braverman, H. (1974). Labor and Monopoly Capital. New York: Monthly Review Press.

Burawoy, M. (1979). Manufacturing Consent. Chicago: The University of Chicago Press.

Burton, J. \& Van den Broek, D. (2009). Accountable and countable: Information management systems and the bureaucratization of social work. British Journal of Social Work, 39(7), 1326-1342

Choudhury, V. \& Sabherwal, R. (2003). Portfolios of control in outsourced software development projects. Information Systems Research, September. 14, 3.

Dalton, M. (1959). Men Who Manage. New York: Wiley.

DiMaggio, P. (1992). Nadel's paradox revisited: relational and cultural aspects of organizational structure. in Networks and Organizations, Nohria, N. \& Eccles, R. G. (Eds.), Harvard Business School Press.

DiMaggio, P. \& Powell, W. W. (1983). The iron cage revisited: institutional isomorphism and collective rationality in organizational fields. American Sociological Review, 48 (April), 147-60.

Durkheim, E. (1957). Professional Ethics and Civic Morals. Routledge.

Feigenbaum, A. V. (1989). How to implement total quality control. Executive Excellence, Nov; 6, 11.

Fine, E. (2001). Where heroes go: the very people who propel a company from start-up to success are often unsuited to staying on as key personnel. IIE Solutions, May, 33, 5.

Fukuyama, F. (1995). Trust: Social Virtues and the Creation of Prosperity. London: Hamish Hamilton.

Gerth, H. H. \& Mills, W. M. (1946). From Max Weber: essays in sociology. Oxford University Press.

Giroux, H. \& Landry, S. (1998). Schools of thought in and against total quality. Journal of Managerial Issues, Vol. 10,2 .

Gouldner, A. (1954). Patterns of Industrial Bureaucracy. New York: Basic Books.

Henry, R. M., Narayanaswamy, R., \& Purvis, R. L. (2015). Effect of control on information systems development performance. The Journal of Computer Information Systems, Spring. 55, 3.

Hill, S. (1995). From Quality Circles to Total Quality Management. In Making Quality Critical - New Perspectives on Organizational Change, Eds. A. Wilkinson and H. Willmott. London: Routledge.

Jackall, R. (1988). Moral Mazes: The World of Corporate Managers. New York: Oxford University Press.

Kanter, R. (1977). Men and Women of the Corporation. New York: Basic Books.

Keil, M., Rai, A., \& Liu, S. (2013). How user risk and requirements risk moderate the effects of formal and informal control on the process performance of IT projects. European Journal of Information Systems, 22, 650-672.

Kirsch, L. J., Sambamurthy, V., Ko, D., \& Purvis, R. L. (2002). Controlling information systems development projects: the view from the client. Management Science, Apr, 48, 4.

Kunda, G. (1992). Engineering Culture. Temple University Press: Philadelphia.

Landen, L. L. \& Landen, G. A. (1990). Please, No More Buzzwords. The Journal for Quality and Participation (March): 26:30. 


\section{Issues in Information Systems}

Volume 19, Issue 1, pp. 29-38, 2018

Long, C. P., Burton, R. M. \& Cardinal, L. B. (2002). Three controls are better than one: a computational model of complex control systems. Computational \& Mathematical Organization Theory, 8, 197-220.

McGarry, C. \& Sweeney, B. (2007). Clan type controls over audit quality - audit seniors' perspectives. The Irish Accounting Review; Winter, 14, 2.

Nahapiet, J. \& Ghoshal, S. (1998). Social Capital, Intellectual Capital, and the Organizational Advantage. Academy of Management Review. Vol. 23, No. 2, 242-66.

Nugent, P. D. (2017). The Shifting Landscape of Professional Work and Power: On the Proliferation of EnterpriseLevel Quality Control Systems. Issues in Information Systems, 17 (I).

Nugent, P. \& Collar, E. (2017). A Critical Examination of the Effects of Enterprise-Level Quality Control Programs on Professional Work. Review of Contemporary Business Research, 6 (1).

Parsons, R. (2003). In defence of clan. Supply Management, April, 8, 9.

Powell, W. W. (1990). Neither Market nor Hierarchy: Network Forms of Organization. in Research in Organizational Behavior, B. M. Staw and L. L. Cummings (Eds.) Vol. 12. pp. 295-336. JAI Press.

Powell, W. W. \& DiMaggio, P. J. (Eds.) (1991). The New Institutionalism in Organizational Analysis. The University of Chicago Press.

Roethlisberger, F. \& Dixon, W. (1939). Management and the Worker. Cambridge, Mass.: Harvard University Press.

Rohlen, T. (1974). For Harmony and Strength: Japanese White Collar Organization in Anthropological Perspective. Berkeley: University of California Press.

Rosen, M. (1984). Power and Culture in Bureaucracy: A Study of Bureaucracy as a Control Mechanism in Monopoly Capitalism. Ph.D. dissertation, University of Pennsylvania.

Roy, D. (1954). Quota Restriction and Goldbricking in a Machine Shop. American Journal of Sociology, 57 : 42742.

Schafer, R. H. \& Thomson, H. A. (1992). Successful Change Programs Begin with Results. Harvard Business Review (January-February): 80-89.

Shang, S. C. \& Lin, S. (2009). Understanding the effectiveness of Capability Maturity Model Integration by examining the knowledge management of software development processes. Business and Economics Management, Vol. 20, 5.

Smith, M. P. (1971). Alienation and Bureaucracy: The Role of Participatory Administration. Public Administration Review, 6, 658-664.

Wiener, M., Remus, U., Heumann, J., \& Mahring, M. (2015). The effective promotion of informal control in information systems offshoring projects. European Journal of Information Systems, 24, 569-587.

Waters, M. (1989). Collegiality, Bureaucratization, and Professionalization: A Weberian Analysis. American Journal of Sociology. Vol. 94, No. 5.

Whyte, W. (1956). The Organization Man. New York: Simon and Schuster. 